\title{
Impact of Intraoperative Dexmedetomidine versus Remifentanil on Recovery Characteristics following Laparoscopic Sleeve Gastrectomy
}

\author{
Abdul Sattar Narejo, Muhammad Musa Khan, Ali Alwhabi, Adel Alqarni, Abdulaziz Ejaz Ahmed and Abdelazeem \\ Ali Eldawlatly \\ Department of Anesthesia, King Saud University Medical City, Riyadh, Saudi Arabia
}

\begin{abstract}
Objective: To evaluate the impact of intraoperative dexmedetomidine versus remifentanil on postoperative pain; and enhanced recovery profile in patients scheduled for laparoscopic sleeve gastrectomy (LSG).

Study Design: Clinical observational double-blind pilot study.

Place and Duration of Study: King Khalid University Hospital, affiliated with King Saud University, Riyadh, Saudi Arabia, from December 2019 to March 2020.

Methodology: Forty adult patients with body mass index (BMI) $>35 \mathrm{Kg} / \mathrm{m}^{2}$ were divided into two equal groups: group dexmedetomidine (D) and group remifentanil (R). In the post-anaesthesia care unit (PACU) and for 24 hours in the ward, the patients were assessed for pain score and other recovery characteristics.

Results: In the PACU, the mean values of numerical rating scale (NRS) were $4.26 \pm 1.97 \mathrm{vs.} 4.15 \pm 1.9$ and morphine consumption median values were 4 vs. $1 \mathrm{mg}$ in groups $D$ and R, respectively $(p>0.05)$. The number of patients who developed shivering were 0 vs. 6 in groups $D$ and $R$, respectively ( $p<0.05$ ). Sedation agitation scale (SAS) median values were 4 vs. 4 ( $p<0.05$ ), postoperative nausea and vomiting (PONV) frequency was 1 vs. $6(p>0.05)$ in groups D and R, respectively. The length of hospital stay (LOS) median values were 1 vs. 1 day in groups $D$ and $R$, respectively ( $p>0.05$ ).

Conclusion: Better enhanced recovery profile after LSG supports the use of intraoperative infusion of dexmedetomidine as an anaesthetic adjuvant versus remifentanil.
\end{abstract}

Key Words: Dexmedetomidine, Remifentanil, Enhanced recovery after surgery (ERAS); Bariatric surgery.

How to cite this article: Narejo AS, Khan MM, Alwhabi A, Alqarni A, Ahmed AE, Eldawlatly AA. Impact of Intraoperative Dexmedetomidine versus Remifentanil on Recovery Characteristics following Laparoscopic Sleeve Gastrectomy. J Coll Physicians Surg Pak 2021; 31(02):210-214.

\section{INTRODUCTION}

The rising prevalence of obesity is a significant concern worldwide. ${ }^{1}$ Laparoscopic sleeve gastrectomy (LSG) is one of the effective treatments for sustained weight loss and to ameliorate the obesity-related comorbidities, such as heart disease, hypertension, diabetes mellitus, stroke, certain types of cancer, and joint problems. ${ }^{2}$ The standard anaesthetic care for LSG starts with careful preoperative assessment and optimisation of comorbidities. Induction and maintenance of anaesthesia, oxygenation, tracheal intubation, and pain management is challenging in these patients. Induction of anaesthesia is conventionally conducted with short-acting drugs, and less soluble volatile agents are preferred for maintenance. ${ }^{3}$

Correspondence to: Dr. Abdul Sattar Narejo, Department of Anesthesia, King Saud University Medical City, Riyadh, Saudi Arabia

E-mail: narejo27@hotmail.com

Received: September 20, 2020; Revised: November 05, 2020; Accepted: December 16, 2020

DOI: https://doi.org/10.29271/jcpsp.2021.02.210
Moreover, obese patients are at higher risk for postoperative complications. ${ }^{4}$ Therefore, to cope up with these challenges and to avoid such complications, the implementation of enhanced recovery after surgery (ERAS) programme in LSG surgery and anaesthesia are not only feasible, but also safe, well-tolerated; and significantly reduces the length of hospital stay (LOS) without increasing complications or re-admission rates. It aims to maintain physiological function, enhance mobilisation, reduce pain, and facilitate early oral nutrition postoperatively by reducing perioperative surgical stress. ${ }^{5}$ Surgery-induced acute postoperative pain, stress response, and fatigue lead to prolonged convalescence and hospital stay. ${ }^{6}$ The adjuvants like dexmedetomidine and remifentanil in morbidly obese patients are used to prevent perioperative stress response to tracheal intubation and extubation, surgery, reduce minimum alveolar concentration (MAC), analgesia, fatigue, delirium, PONV and shivering ${ }^{7.8}$ Currently, LSG is considered as most popular procedure for weight loss worldwide with short operational time. ${ }^{9}$ Implementation of ERAS rationalised the use of such anaesthetic agents which can cope up with fast turnover.

The objective of this study was to compare pain score and the 
recovery profile characteristics, following intraoperative use of dexmedetomidine versus remifentanil in obese patients scheduled to undergo LSG.

\section{METHODOLOGY}

Informed written consents were obtained from 40 adult patients of either gender, age 18-60 years, American Society of Anaesthesiologists (ASA) II-III, BMI $>35 \mathrm{Kg} / \mathrm{m}^{2}$ scheduled to undergo elective LSG were included in this study. Patients with ASA > III, uncontrolled hypertension and diabetes mellitus, heart block $>1^{\text {st }}$ degree, allergic to morphine or alpha- 2 receptor agonist drugs, clinically significant neurological, cardiovascular, renal or hepatic diseases, history of drug abuse or chronic opioid use, were excluded from the study. Randomisation was computer-generated and concealed from patients and investigators until completion of statistical analysis.

The same surgical team performed LSG for all patients in the study. Patients were randomly assigned into two equal groups: group D(Dexmedetomidine) and group R (Remifentanil). Intraoperative monitoring was according to the local protocol and included peripheral nerve stimulator (PNS). Anaesthesia drugs doses were calculated according to ideal body weight (IBW) and adjusted body weight (AjBW) using the link http://globalrph.com/medcalcs/adjusted - body - weight - ajbw and - ideal - body - weight - ibw - calc/. Anaesthesia was induced with fentanyl $2 \mathrm{mcg} / \mathrm{Kg}$, propofol $2 \mathrm{mg} / \mathrm{Kg}$, followed by rocuronium $1 \mathrm{mg} / \mathrm{Kg}$ to facilitate tracheal intubation. Respective infusion started after induction based on the total body weight (TBW). To standardise the dilutions, dexmedetomidine [Precedex (Pfizer)] 200 mcg was diluted in $50 \mathrm{ml}$ syringe with normal saline renders the final concentration $4 \mathrm{mcg} / \mathrm{ml}$. Dexmedetomidine was given at a dose of $0.2-0.7 \mathrm{mcg} / \mathrm{Kg} / \mathrm{hour}$. Remifentanil [Ultiva (Abbott)] $5 \mathrm{mg}$ was diluted in $50 \mathrm{ml}$ syringe with normal saline. The final concentration was $100 \mathrm{mcg} / \mathrm{ml}$. Remifentanil infusion was given at a dose of 0.05-1 $\mathrm{mcg} / \mathrm{Kg} / \mathrm{minute}$. General anaesthesia was maintained with desflurane MAC value of $0.7-1$ in $50 \% \mathrm{O}_{2}$. Intravenous ephedrine $5 \mathrm{mg} / \mathrm{ml}$ used as a rescue medication for mean arterial pressure (MAP) below $65 \mathrm{mmHg}$. Intravenous dexamethasone $8 \mathrm{mg}$, ondansetron $8 \mathrm{mg}$ and paracetamol $\mathrm{lg}$ were given intraoperatively to all patients. Ten minutes before the end of surgery, injection morphine $0.08 \mathrm{mg} / \mathrm{Kg}$ of IBW was given intravenously. At skin closure, desflurane was discontinued, and $2 \mathrm{mg} / \mathrm{Kg}$ of AJBW sugammadex was given after the appearance of two twitches on PNS. After tracheal extubation, respective infusion was discontinued; then all patients were transferred to PACU. After they achieved a modified Aldrete score of 9 on two sequential measurements of 10 minutes interval, they were discharged to the ward. Pain in PACU was measured by NRS scale at admission, then every 15 minutes, and in the ward every 4 hours till the next 24 hours. In PACU, morphine 2 mg for pain was given every 15 minutes boluses until NRS $<4$, discontinued on sedation score $<2$ or respiratory rate $<10$ breaths/minute. Sedation and agitation were assessed using the riker sedation agitation scale (SAS). ${ }^{10}$ Score $\geq 5$ was defined as agitated. All intraoperative and postoperative data were collected by anaesthesia assistant not involved in the study and blinded to group allocation.

The primary outcome was to evaluate pain. The secondary outcomes were morphine consumption and enhanced recovery, including the duration of surgery, time of awakening, time of tracheal extubation, SAS, shivering, NRS, PONV and LOS.

Statistical analysis was performed using statistical package for the social sciences (SPSS) version 24.0 software (SPSS Inc., Chicago, IL, USA). Frequencies and percentages of all nominal variables, and mean, standard deviation (SD), median and (IQR: Q1-Q3) for all measurable numerical variables were calculated). Shapiro-Wilk test was used for normality. Chi-square test $\left(\chi^{2}\right)$ or Fisher's Exact test was used to compare the two groups concerning nominal variables (ASA, gender, shivering and PONV). Student's t-test or Mann-Whitney U-test was used for two independent groups to compare the two groups concerning measurable variables (age, $\mathrm{BMI}, \mathrm{CBW}, \mathrm{H} / \mathrm{R}, \mathrm{MAP}, \mathrm{SpO}_{2}$ ). pvalues below $0.05(p<0.05)$ were considered significant.

\section{RESULTS}

Both groups had comparable demographic variables (Table I). Although, intraoperatively the mean arterial pressure (MAP) in both groups was within the normal physiological range. Statistically, D group MAP was lower than R group patients 76.21 \pm 2.10 vs. $83.50 \pm 9.09 \mathrm{mmHg}(p=0.039)$. Intraoperative and postoperative heart rate was statistically insignificant, comparing the two groups ( $p=0.755)$. Similarly, both groups required almost same amount of ephedrine $D=10$ vs. $R=10 \mathrm{mg}$, $(p=0.367)$. The duration of surgery and time required for the patient to wake up after closing desflurane were statistically insignificant in both groups $(p>0.05)$. The time of tracheal extubation was shorter in $\mathrm{D}$ group compared to R group, 2 vs. 5 minutes ( $p<0.001$ ). Overall, the course of anaesthesia and surgery intraoperatively was uneventful (Table II). In PACU, although D group MAP was lower than $\mathrm{R}$ group, $84.0 \pm 11.72$ vs. $96.15 \pm 14.58 \mathrm{mmHg}(p=0.008)$, hemodynamically both groups remain stable.

Regarding SAS score, D group patients were sedated but responding to verbal stimuli compared with $\mathrm{R}$ group, who were calm and followed commands $(D=4$ vs. $R=4, p=0.004)$ ). No patient complained of shivering in $\mathrm{D}$ group, wherein $\mathrm{R}$ group 6 patients did $(p=0.020)$. PONV was higher in $R$ group compared to $D$ group, $D=1$ vs. $R=6$ patients, but statistically insignificant $(P=0.091)$. The duration of PACU stay was statistically insignificant in both groups. The NRS in both groups were $D=4.26 \pm 1.97$ vs. $R=4.15 \pm 1.93$ ( $p=0.857$ ). Similarly, morphine consumption in both groups was $D=4$ vs. $R=1 \mathrm{mg}(p=0.330)$ (Table III). After the average duration ( 47 minutes) atPACU stay, all patients were shifted to the ward. Statistically, the pain score in D group was higher compared to R group in the ward, 5 vs. 1 ( $p<0.001$ ). Morphine consumption in 24 hours was statistically insignificant, 10 vs. $10 \mathrm{mg}$ in groups $\mathrm{D}$ and $\mathrm{R}$, respectively ( $p=0.782$ ). PONV was significantly higher in $\mathrm{R}$ group 13 , compared to $\mathrm{D}$ group 3 patients $(p=0.001)$. Similarly, rescue metoclopramide given to $R$ group was $10 \mathrm{mg}$ versus $0 \mathrm{mg}$ in $\mathrm{D}$ group $(p=0.001)$. LOS comparing both groups was statistically insignificant $(p=0.616)$ 
(Table III).

Table I: Demographic data comparing dexmedetomidine and remifentanil groups.

\begin{tabular}{|c|c|c|c|}
\hline & \multicolumn{2}{|c|}{ Group } & \multirow[t]{3}{*}{ p-value } \\
\hline & Dexmedetomidine $(\mathrm{n}=\mathbf{2 0})$ & Remifentanil ( $n=20$ ) & \\
\hline & $\begin{array}{c}\text { Mean } \pm \text { SD } \\
\text { Median (Q1 - Q3) }\end{array}$ & $\begin{array}{c}\text { Mean } \pm \text { SD } \\
\text { Median (Q1 - Q3) }\end{array}$ & \\
\hline $\begin{array}{l}\text { Gender } \\
\text { Male } \\
\text { Female }\end{array}$ & $\begin{array}{c}6(30 \%) \\
14(70 \%)\end{array}$ & $\begin{array}{c}7(35 \%) \\
13(65 \%)\end{array}$ & $0.736^{* *}$ \\
\hline $\begin{array}{l}\text { ASA } \\
\text { II } \\
\text { III } \\
\end{array}$ & $\begin{array}{l}16(80 \%) \\
4(20 \%)\end{array}$ & $\begin{array}{l}16(80 \%) \\
4(20 \%)\end{array}$ & $>0.999^{\#}$ \\
\hline Age (years) & $\begin{array}{c}38.05 \pm 11.33 \\
36.5(30.25-50.25)\end{array}$ & $\begin{array}{c}31.45 \pm 10.23 \\
30(25-36.75)\end{array}$ & $0.061^{*}$ \\
\hline $\mathrm{BMI} \mathrm{kg} / \mathrm{m} 2$ & $\begin{array}{l}45.05 \pm 6.21 \\
45(40-50)\end{array}$ & $\begin{array}{c}45.33 \pm 6.06 \\
43.97(41.60-49.20)\end{array}$ & $0.957^{* * *}$ \\
\hline AjBW & $\begin{array}{c}79.05 \pm 9.19 \\
78.5(74-84.5)\end{array}$ & $\begin{array}{c}83.45 \pm 14.73 \\
80.5(71.5-96.5)\end{array}$ & $0.266 *$ \\
\hline
\end{tabular}

Table II: Intra-operative data comparing hemodynamic and recovery characteristics.

\begin{tabular}{|c|c|c|c|}
\hline & \multicolumn{2}{|r|}{ Group } & \multirow[t]{3}{*}{ p-value } \\
\hline & Dexmedetomidine $(n=20)$ & Remifentanil ( $n=20)$ & \\
\hline & $\begin{array}{c}\text { Mean } \pm \text { SD } \\
\text { Median }(\mathrm{Q} 1-\mathrm{Q} 3) \\
\end{array}$ & $\begin{array}{c}\text { Mean } \pm \text { SD } \\
\text { Median }(\mathrm{Q} 1-\mathrm{Q} 3) \\
\end{array}$ & \\
\hline Heart rate (beats/min) & $\begin{array}{c}80.70 \pm 9.91 \\
77.5(74.25-89.75)\end{array}$ & $\begin{array}{c}81.80 \pm 12.09 \\
82.5(71.5-91.25)\end{array}$ & $0.755^{*}$ \\
\hline Mean arterial pressure (MAP) (mmHg) & $\begin{array}{c}76.21 \pm 12.10 \\
72(64-88)\end{array}$ & $\begin{array}{l}83.50 \pm 9.09 \\
84(75.5-92)\end{array}$ & $0.039 *$ \\
\hline Spo2 & $\begin{array}{c}98.75 \pm 0.97 \\
99(98-99.75)\end{array}$ & $\begin{array}{l}98.55 \pm 1.05 \\
99(98-99)\end{array}$ & $0.564 * *$ \\
\hline Ephedrine (mg) & $\begin{array}{l}9.20 \pm 1.79 \\
10(8-10)\end{array}$ & $\begin{array}{l}8.13 \pm 2.59 \\
10(5-10)\end{array}$ & $0.367 * *$ \\
\hline Duration of surgery (min) & $\begin{array}{c}74.60 \pm 23.19 \\
74.5(60-83.75)\end{array}$ & $\begin{array}{c}63.25 \pm 16.18 \\
60(55-68)\end{array}$ & $0.092 * *$ \\
\hline Time of awaken (min) & $\begin{array}{c}3.90 \pm 1.80 \\
4(2-5)\end{array}$ & $\begin{array}{l}3.65 \pm 2.16 \\
3(2-4.75)\end{array}$ & $0.465^{* *}$ \\
\hline Time of extubation (min) & $\begin{array}{c}2.75 \pm 1.48 \\
2(2-4)\end{array}$ & $\begin{array}{c}5.55 \pm 2.52 \\
5(4-6)\end{array}$ & $<0.001^{* *}$ \\
\hline
\end{tabular}

\section{DISCUSSION}

In this study, the patients, who received intraoperative dexmedetomidine infusion, had no postoperative shivering and less PONV as compared to those who received remifentanil, which resulted in better recovery profile and faster discharge from PACU. Although both groups had almost the same intensity of pain in PACU, dexmedetomidine group reported more pain in the ward compared to remifentanil group, though consumed almost the same amount of morphine. Most of our patients were discharged home on first-day following LSG. There is little evidence to favour one anaesthetic adjuvant technique over another, but the general principles of enhanced recovery, support the use of medications that have a minimal postoperative hangover and minimal effects on gastric motility. ${ }^{11}$ Thus, short-acting premedicants and volatile anaesthetics or total intravenous anaesthesia with short-acting agents are preferred. ${ }^{12}$
As obese patients have altered pharmacokinetics and pharmacodynamics, and due to fear of opioid side effects, these patients are often undertreated for postoperative pain. ${ }^{12}$

Taylor et al. in a retrospective analysis, attributed that $77 \%$ of morbidity occurs due to opioids in the first postoperative day in high-risk obese patients. ${ }^{13}$

On the other hand, remifentanil has favourable pharmacokinetic properties, minimally altered by extremes of age or renal or hepatic dysfunction, enable easy titration and rapid dissipation of clinical effect of this agent, even after prolonged infusion. ${ }^{14}$ Bekker et al. reported, dexmedetomidine by modulating endocrine and inflammatory response alleviates postoperative fatigue, delirium and shortens the postoperative convalescence period. ${ }^{15}$ Similarly, Tufanogullari et al. reported that intraoperative dexmedetomidine infusion in obese patients reduces anaesthetic consumption, maintains cardiovascular stability, promotes early recovery, reduces PACU stay by reducing intraoperative and postopera- 
tive opioid requirements, and emetic symptoms. ${ }^{16}$

Table III: Postoperative recovery characteristics data in PACU and ward.

\begin{tabular}{|c|c|c|c|c|}
\hline & & & Group & *p-value \\
\hline & & $\begin{array}{l}\text { Dexmedetomidine } \\
(\mathrm{n}=20)\end{array}$ & $\begin{array}{l}\text { Remifentanil } \\
\quad(n=20)\end{array}$ & \\
\hline & & $\begin{array}{c}\text { Mean } \pm \text { SD } \\
\text { Median }(\mathrm{Q} 1-\mathrm{Q} 3)\end{array}$ & $\begin{array}{c}\text { Mean } \pm \text { SD } \\
\text { Median (Q1 - Q3) }\end{array}$ & \\
\hline & Heart rate (beats/min) & $\begin{array}{c}74.17 \pm 11.19 \\
72(65.75-84.50)\end{array}$ & $\begin{array}{l}78.45 \pm 13.80 \\
77(70-86.5)\end{array}$ & $0.298 *$ \\
\hline & $\begin{array}{l}\text { Mean Arterial blood pressure (MAP) } \\
(\mathrm{mmHg})\end{array}$ & $\begin{array}{c}84.0 \pm 11.72 \\
83.5(76.25-91.25)\end{array}$ & $\begin{array}{c}96.15 \pm 14.58 \\
99(83-107.75)\end{array}$ & $0.008 *$ \\
\hline & Spo2 (\%) & $\begin{array}{l}99.18 \pm 1.02 \\
99(99-100)\end{array}$ & $\begin{array}{c}98.40 \pm 2.76 \\
99(98.25-99)\end{array}$ & $0.169 * * *$ \\
\hline PACU & $\begin{array}{l}\text { Shivering } \\
\text { Yes } \\
\text { No } \\
\end{array}$ & $\begin{array}{c}0(0 \%) \\
20(100 \%)\end{array}$ & $\begin{array}{l}6(30.0 \%) \\
14(70 \%)\end{array}$ & $0.02^{\#}$ \\
\hline & NRS $(0-10)$ & $\begin{array}{l}4.26 \pm 1.97 \\
5(3-5)\end{array}$ & $\begin{array}{l}4.15 \pm 1.93 \\
4(3-6)\end{array}$ & $0.857^{*}$ \\
\hline & SAS (1-7) & $\begin{array}{l}3.74 \pm 0.45 \\
4(3-4)\end{array}$ & $\begin{array}{l}4.25 \pm 0.55 \\
4(4-5)\end{array}$ & $0.004^{* * *}$ \\
\hline & $\begin{array}{l}\text { PONV } \\
\text { Yes } \\
\text { No } \\
\end{array}$ & $\begin{array}{c}1(5.0 \%) \\
19(95.0 \%)\end{array}$ & $\begin{array}{c}6(30.0 \%) \\
14(70.0 \%)\end{array}$ & $0.091^{\#}$ \\
\hline & PACU (min) & $\begin{array}{c}47.35 \pm 8.56 \\
45.5(40-50.75)\end{array}$ & $\begin{array}{c}51.80 \pm 8.33 \\
50(45-59.25)\end{array}$ & $0.095^{* * *}$ \\
\hline & Morphine (mg) & $\begin{array}{l}3.70 \pm 2.68 \\
4(2-6)\end{array}$ & $\begin{array}{l}3.0 \pm 3.58 \\
1(0-6)\end{array}$ & $0.330 * * *$ \\
\hline & Metoclopramide (mg) & $\begin{array}{l}0.50 \pm 2.24 \\
0(0-0)\end{array}$ & $\begin{array}{c}2.0 \pm 4.10 \\
0(0-0)\end{array}$ & $0.157^{* * *}$ \\
\hline & NRS $(0-10)$ & $\begin{array}{l}4.85 \pm 1.23 \\
5(4-5.75)\end{array}$ & $\begin{array}{l}1.55 \pm 1.73 \\
1(0-3.75)\end{array}$ & $<0.001^{* * *}$ \\
\hline & Morphine $(\mathrm{mg})$ in $24 \mathrm{~h}$ & $\begin{array}{l}10.45 \pm 4.29 \\
10(8-13.5)\end{array}$ & $\begin{array}{c}11.05 \pm 4.12 \\
10(10-14)\end{array}$ & $0.782^{* * *}$ \\
\hline WARD & Metoclopramide (mg) & $\begin{array}{l}1.50 \pm 3.66 \\
0(0-0)\end{array}$ & $\begin{array}{c}13.0 \pm 16.58 \\
10(0-17.50)\end{array}$ & $0.001^{* * *}$ \\
\hline & LOS (days) & $\begin{array}{c}1.42 \pm 0.61 \\
1(1-2)\end{array}$ & $\begin{array}{l}1.40 \pm 0.75 \\
1(1-1.75)\end{array}$ & $0.616^{* * *}$ \\
\hline & $\begin{array}{l}\text { PONV } \\
\text { Yes } \\
\text { No }\end{array}$ & $\begin{array}{c}3(15.0 \%) \\
17(85.0 \%)\end{array}$ & $\begin{array}{l}13(65.0 \%) \\
7(35.0 \%)\end{array}$ & $0.001 * *$ \\
\hline
\end{tabular}

PONV, rigour, and restlessness are common adverse effects of anaesthesia and surgery, which leads to decreasing the quality of life and prolonged convalescence with longer LOS. Dexmedetomidine provides better intraoperative hemodynamic response and postoperative analgesia compared to remifentanil. ${ }^{17}$ Similar to this study, many researchers investigated the impact of dexmedetomidine on postoperative pain after abdominal surgery. Dexmedetomidine decreases sympathovagal balance better than opioids intraoperatively; and during abdominal surgeries, provides adequate postoperative analgesia and reduces morphine consumption. ${ }^{18}$ The limitations of this study include small sample size, being a pilot study without sample size calculation, and lack of a control group.

\section{CONCLUSION}

Better/enhanced recovery profile after LSG supports the use of intraoperative infusion of dexmedetomidine as an anaesthetic adjuvant versus remifentanil infusion.

\section{FUNDING:}

The study was supported and funded by the Saudi Anesthesia Society (SAS).

\section{ACKNOWLEDGEMENT:}

Thankful to the College of Medicine Research Centre and Deanship of Scientific Research, King Saud University, Riyadh, Saudi Arabia. Moreover, the authors would like to thank Mr Amir Marzouk for statistical analysis of the data obtained.

\section{ETHICAL APPROVAL:}

This study was conducted in compliance with the ethical principles, according to the Declaration of Helsinki, and it was initiated after the approval by the local Institutional Review Board (IRB) of King Khalid University Hospital, affiliated with King Saud University, Riyadh, Saudi Arabia. Research project number E-19-434. Registered via UMIN-CTR Clinical Trial 
Registry, UMIN000040880.

\section{PATIENTS' CONSENT:}

All participants included in this study had informed and signed written consents after IRB approvals, and allowed us to use their data for publication.

\section{CONFLICT OF INTEREST:}

All authors of this study declared no conflict of interest.

\section{AUTHORS' CONTRIBUTION:}

ASN, MMK: Conception and design of the work, data acquisition and interpretation, manuscript drafting and revision.

$A A, A A, A A$ : Conception and design of the work, data acquisition and interpretation, revision and editing.

$A A E$ : Conception and design of the work, supervision, monitoring, and critical revision of the manuscript.

All the authors critically reviewed the final version of the manuscript and approved the final draft for accountability.

\section{REFERENCES}

1. Reilly JJ, El-Hamdouchi A, Diouf A, Monyeki A, Somda SA. Determining the worldwide prevalence of obesity. Lancet 2018; 391(10132):1773-4. doi: 10.1016/S0140-6736(18) 30794-3.

2. Segula D. Cmplations of obesity in adults: A short review of the literature. Malawi Med J 2014; 26(1):20-4.

3. Trotta M, Ferrari C, D'Alessandro G, Sarra G, Piscitelli G, Marinari GM. Enhanced recovery after bariatric surgery (ERABS) in a high-volume bariatric centre. Surg Obes Relat Dis 2019; 15(10):1785-92. doi: 10.1016/j.soard.2019. 06.038.

4. Soleimanpour H, Safari S, Sanaie S, Nazari M, Alavian SM. Anaesthetic considerations in patients undergoing bariatric surgery: A review article. Anesthesiol Pain Med 2017; 7(4):57568. doi: 10.5812/aapm.57568.

5. Awad S, Carter S, Purkayastha S, Hakky S, Moorthy K, Cousins J, et al. Enhanced recovery after bariatric surgery (ERABS): Clinical outcomes from a tertiary referral bariatric centre. Obesity Surg 2014; 24(5):753-8. doi: 10.1007/ s11695-013-1151-4.

6. Ge DJ, Qi B, Tang G, Li JY. Intraoperative dexmedetomidine promotes postoperative analgesia and recovery in patients after abdominal hysterectomy: A double-blind, randomised clinical trial. Sci Rep 2016; 6:21514. doi: 10.1038/srep 21514.

7. Grape S, Kirkham KR, Frauenknecht J, Albrecht E. Intra-operative analgesia with remifentanil vs. dexmedetomidine: A systematic review and meta-analysis with trial sequential analysis. Anaesthesia 2019; 74(6):793-800. doi: 10.1111/ anae.14657.
8. Hamed JME, Refaat HSM, Wadaani HA. Dexmedetomidine compared to remifentanil infusion as adjuvant to sevoflurane anesthesia during laparoscopic sleeve gastrectomy. Anesth Essays Res 2019; 13(4):636-42. doi: 10.4103/ aer.AER_126_19.

9. Shi X, Karmali S, Sharma A, Birch D. A review of laparoscopic sleeve gastrectomy for morbid obesity. Obes Surg 2010; 20(8):1171-7. doi: 10.1007/s11695-010-0145-8.

10. Riker RR, Fraser GL, Simmons LE, Wilkins ML. Validating the sedation-agitation scale with the bispectral index and visual analogue scale in adult ICU patients after cardiac surgery. Intensive Care Med 2001; 27(5):853-8. doi: 10.1007/s001 340100912.

11. Gustafsson UO, Scott MJ, Hubner M, Nygren J, Demartines N, Francis N, et al. Guidelines for perioperative care in elective colorectal surgery: Enhanced recovery after surgery (eras (B) society recommendations: 2018. Wrld J Surg 2019; 43(3):659-95. doi: 10.1007/s00268-018-4844-y.

12. Nimmo AF, Absalom AR, Bagshaw O, Biswas A, Cook TM, Costello $A$, et al. Guidelines for the safe practice of total intravenous anaesthesia (TIVA): Joint guidelines from the association of anaesthetists and the society for intravenous anaesthesia. Anaesthesia 2019; 74(2):211-24. doi: 10.1111/anae.14428.

13. Taylor S, Kirton OC, Staff I, Kozol RA. Postoperative day one: A high risk period for respiratory events. Am J Surg 2005; 190(5):752-6. doi: 10.1016/j.amjsurg.2005.07.015.

14. Cascone S, Lamberti G, Piazza O, Abbiati RA, Manca D. A physiologically-based model to predict individual pharmacokinetics and pharmacodynamics of remifentanil. Eur J Pharm Sci 2018; 111:20-8. doi: 10.1016/j.ejps.2017. 09.028.

15. Bekker A, Haile M, Kline R, Didehvar S, Babu R, Martiniuk F, et al. The effect of intraoperative infusion of dexmedetomidine on the quality of recovery after major spinal surgery. $J$ Neurosurg Anesthesiol 2013; 25(1):16-24. doi: 10.1097/ANA.0b013e31826318af.

16. Tufanogullari B, White PF, Peixoto MP, Kianpour D, Lacour T, Griffin J, et al. Dexmedetomidine infusion during laparoscopic bariatric surgery: The effect on recovery outcome variables. Anesth Analg 2008; 106(6):1741-8. doi: 10.1213/ ane.0b013e318172c47c.

17. Rajan S, Hutcherson MT, Sessler DI, Kurz A, Yang D, Ghobrial $M$, et al. The effects of dexmedetomidine and remifentanil on hemodynamic stability and analgesic requirement after craniotomy: A randomised controlled trial. J Neurosurg Anesthesiol 2016; 28(4):282-90. doi: 10.1097/ANA.000000000 0000221.

18. Vora KS, Baranda U, Shah VR, Modi M, Parikh GP, Butala BP. The effects of dexmedetomidine on attenuation of hemodynamic changes and there effects as an adjuvant in anaesthesia during laparoscopic surgeries. Saudi J Anaesth 2015; 9(4):386-92. doi: 10.4103/1658-354X.159461. 